\title{
Intervention to Improve School Teacher Confidence in Asthma Management
}

\author{
Marina Reznik, MD, MS and Philip O. Ozuah, MD, PhD.
}

Children's Hospital at Montefiore, Montefiore Medical Center, Albert Einstein College of Medicine

\section{BACKGROUND}

Children spend nearly half of their day in school under the supervision of teachers.

- Uncontrolled asthma is common among urban school-age children.

$>$ It is important that school teachers are prepared to help manage students' asthma.

> However, studies show that many teachers lack confidence in student asthma management.

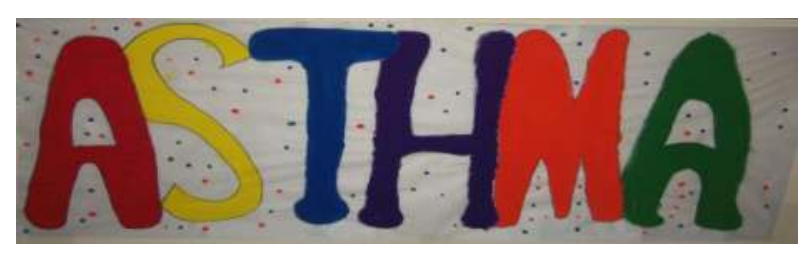

\section{OBJECTIVE}

To evaluate the effectiveness of an educational workshop on school teachers' confidence in asthma management

\section{METHODS}

Design: Pre-post intervention study

Participants: Classroom teachers

Setting: 4 Bronx, New York elementary schools

Intervention:

- A 45-minute asthma workshop delivered by community health worker.

- The workshop reviewed asthma symptoms, triggers, and management of acute attacks as per the National Heart, Lung, and Blood Institute (NHLBI) guidelines on asthma management in schools.

\section{Measures:}

- Teachers completed a 20-item self-completion questionnaire evaluating comfort and confidence (selfefficacy) in school asthma management before and after the intervention.

- We asked teachers about comfort and confidence managing students with asthma, including symptom recognition, trigger avoidance, communicating with parents, encouraging participation in activity, and responding to emergencies.

- A 12-item self-efficacy scale (Chronbach's alpha=.88) was developed.

- Teachers rated their confidence from 5="completely sure" to $1=$ "not at all sure".

\section{Statistical Analysis}

- Paired t-test and McNemar test were used to compare before and after scores.

\section{RESULTS}

A total of $64 / 70$ (91\%) teachers completed pre- and postintervention surveys:

- 95.3\% Female

25.0\% Hispanic; 37.1\% African American

Mean age: 39.7 (SD 10.6) years

Mean years of experience: 8.0 (SD 5.9) years

\section{RESULTS}

Fewer teachers reported feeling worried if a student developed an asthma attack in the classroom postintervention compared to pre-intervention:

$24.6 \%$ vs. $42.9 \%, p=.012$

Post-intervention, teachers were more confident on 8 out of 12 asthma management items (Table)

\section{Table. Teacher Confidence in Asthma Management}

\begin{tabular}{|l|c|c|c|}
\hline \multicolumn{1}{|c|}{ Survey Item } & Pre-test \% & Post-test \% & P Value \\
\hline $\begin{array}{l}\text { Ensuring recognition of } \\
\text { asthma symptoms }\end{array}$ & 32.8 & 64.1 & $<.0001$ \\
\hline $\begin{array}{l}\text { Ensuring avoidance of } \\
\text { asthma triggers in the }\end{array}$ & 30.6 & 54.8 & $\mathbf{. 0 0 3}$ \\
\hline
\end{tabular}

asthma triggers in the classroom

Assisting children with avoidance /exposure to

$29.7 \quad 57.8$

.001 triggers

Ensuring participation of students with asthma in PA.

Assisting students with taking their asthma inhaler

Ensuring immediate access to asthma inhaler in school

Evaluating student's need to take asthma inhaler

Effective communication with parents about child's asthma

Getting immediate medical care for a student in severe distress

Effectively working with nurse and PE teacher to support students with asthma

Ensuring students file a medication administration form

Ensuring immediate access to asthma inhaler during trips

$\mathrm{PA}=$ Physical Activity; $\mathrm{PE}=$ Physical Education

\section{CONCLUSIONS}

A brief asthma workshop incorporating national guidelines on school asthma management improved teacher confidence in managing asthma.

Delivering a sustainable model of annual asthma workshop for school personnel may improve their confidence in assisting with asthma management for students

Funding: NIH-NICHD, K23HD065742; Stony Wold-Herbert Fund

Contact: Marina Reznik, mreznik@montefiore.org 